\title{
Hurricane Alley SST Variability in 2005 and 2006*
}

\author{
ANDREW M. CHIODI \\ Joint Institute for the Study of the Atmosphere and Ocean, University of Washington, Seattle, Washington
}

DON E. HARRISON

Joint Institute for the Study of the Atmosphere and Ocean, University of Washington, and NOAA/Pacific Marine Environmental Laboratory, Seattle, Washington

(Manuscript received 6 June 2007, in final form 11 January 2008)

\begin{abstract}
The North Atlantic hurricane seasons of 2005 and 2006 were dramatically different for the Gulf Coast and eastern seaboard of the United States. The 2005 hurricane season was one of the most destructive seasons in history, whereas there was limited impact in 2006. Hurricane activity had been forecast to be above normal in 2006, but it was not. One of the conspicuous differences in environmental conditions between these two years was sea surface temperature anomaly (SSTA) over a region of the western Atlantic and Caribbean $\left(15^{\circ}-30^{\circ} \mathrm{N}, 70^{\circ}-40^{\circ} \mathrm{W}\right)$, which is important for hurricane formation and intensification. SSTA was more than 1.5 standard deviations warmer during the 2005 hurricane season, but it was much less in 2006 through most of its hurricane season. The intent of this study is to determine the mechanisms responsible for this SSTA difference. It is shown that the difference can be reproduced using a simple one-dimensional (1D) ocean mixed layer model forced with surface fluxes from the NCEP-NCAR reanalysis project. It is found that there are two causes of SSTA difference over this region during July through September: the first is latent heat flux variability caused by wind speed effects, and the second is nonlinear ocean warming caused by submonthly atmospheric variability. The observed SSTA difference is reproduced by our model even though solar forcing damps the observed difference, contrary to previous hypotheses.
\end{abstract}

\section{Introduction}

In their comparison of the hurricane season conditions during 2005 and 2006, Lau and Kim (2007) have recently focused attention on sea surface temperature (SST) anomalies in a region of the western Atlantic and Caribbean (WAC) that is thought to be important to hurricane formation. By their description, the 2005 North Atlantic hurricanes may be divided into two groups: those that form in the eastern tropics and circulate clockwise around the ocean basin east of $65^{\circ} \mathrm{W}$, and those, of interest here, that form over the warm

\footnotetext{
* Pacific Marine Environmental Laboratory Contribution Number 3083 and Joint Institute for the Study of the Atmosphere and Ocean Contribution Number 1415.

Corresponding author address: Andrew Chiodi, NOAA R/Pacific Marine Environmental Laboratory, 7600 Sand Point Way NE, Seattle, WA 98115-6349.

E-mail: andy.chiodi@noaa.gov
}

waters of the WAC region and the Gulf of Mexico. Five of these hurricanes made landfall over the Gulf Coast and the eastern seaboard of the United States in 2005; the first of these landfalls occurred in early July 2005. In 2006, however, there were no hurricanes in the WAC region and the Gulf of Mexico. Although SST in the Gulf of Mexico was warmer in 2006 than in 2005, over the WAC region (study area $15^{\circ}-30^{\circ} \mathrm{N}, 70^{\circ}-40^{\circ} \mathrm{W}$; see Fig. 1) the SST was significantly cooler in July, August, and September (JAS) 2006 than in JAS 2005.

Several studies have found significant correlations between Atlantic hurricane activity and SST in the Gulf of Mexico, the Caribbean Sea, and the tropical and subtropical North Atlantic (e.g., Wang et al. 2006; Emanuel 2005; Saunders and Harris 1997; Shapiro and Goldenberg 1998; Landsea et al. 1999; Molinari and Mestas-Nuñez 2003; Webster 2005; Hoyos et al. 2006). In particular, large warm ( $>2$ standard deviations) SST anomalies, observed near the region of interest here, have previously been linked to the unusually active hurricane seasons of 1995 and 1996 (see Saunders and Har- 


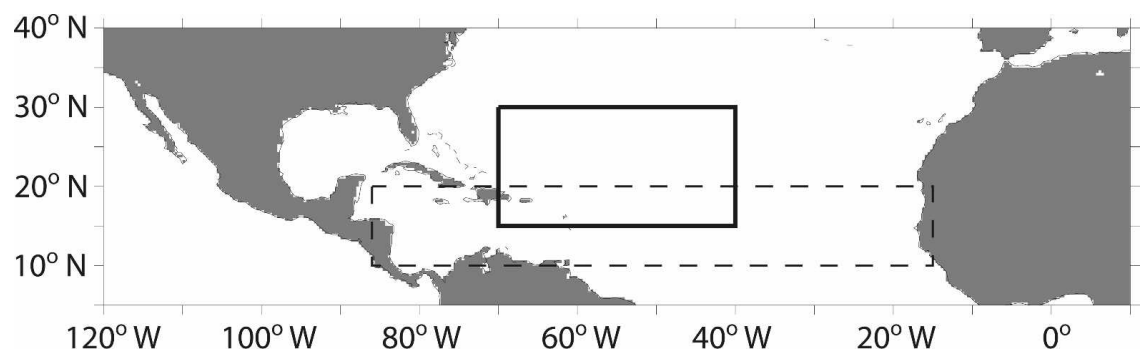

FIG. 1. WAC study region (solid-line rectangle drawn about $15^{\circ}-30^{\circ} \mathrm{N}, 70^{\circ}-40^{\circ} \mathrm{W}$ ) as defined by Lau and Kim (2007) and the MDR (dashed-line rectangle with meridional boundaries at $10^{\circ}$ and $\left.20^{\circ} \mathrm{N}\right)$.

ris 1997; Kimberlain and Elsner 1998). Furthermore, observational and modeling studies have shown that the initial structure and contemporaneous evolution of SST anomalies are fundamentally important to the development of individual hurricanes (Shay et al. 2000; Bender and Ginis 2000).

The primary source of energy for hurricanes is the transfer of heat from the ocean to the atmosphere (Miller 1958; Emanuel 2003). Theoretical considerations have previously shown that an upper bound on the intensity of mature hurricanes [potential intensity (PI)] can be determined from the air-sea thermodynamic disequilibrium (the enthalpy difference between the surface and near-surface atmosphere) and the temperatures of the sea surface, and the upper troposphere and lower stratosphere (Emanuel 1995; Holland 1997; Emanuel 2003). Furthermore, PI has been shown to limit observed tropical cyclone and hurricane intensity (Emanuel 2000). According to this theory, SST controls hurricane intensity only to the extent that it affects PI.

Although it is generally agreed that SST is conditionally important to hurricane activity, it should be noted that other environmental variables, such as vertical wind shear over the central Atlantic, Sahel rainfall (e.g., Goldenberg and Shapiro 1996; Landsea and Gray 1992), and Caribbean sea level pressure (SLP; e.g., Brennan 1935), have also been found to be important to and sometimes the controlling factor of hurricane activity [see Landsea et al. (1999) and Shapiro and Goldenberg (1998) for the case for vertical wind shear]. It is not the intent of this paper to settle the debate over the dominance of these variables, but rather to determine the mechanisms responsible for the 2006-2005 WAC SST difference. This is motivated by the suggestion that WAC SST is important to regional hurricane formation.

Noting an increase in atmospheric dust loading in the northwestern tropical and subtropical Atlantic in 2006, Lau and Kim (2007) have suggested that the dust shielding of solar radiation is primarily responsible for the observed 2006 minus 2005 SST difference in the WAC region. They also suggested that the increased wind speed in 2006 may play a role, through its effect on either latent heat flux or wind mixing. Here, we examine these hypotheses by integrating daily mean surface fluxes of heat and momentum from the National Centers for Environmental Prediction-National Center for Atmospheric Research (NCEP-NCAR) reanalysis project into the simple one-dimensional (1D) mixed layer model described by Price et al. (1986). Results show that increased evaporation, caused by increased 2006 minus 2005 wind speed, is mostly responsible for the observed JAS SST difference; the nonlinear effects of submonthly atmospheric variability on the net fluxes are shown to play an almost equally important role during September. The solar forcing used here, which does not include the dust loading effects discussed by Lau and Kim, damps the observed SST difference.

Because environmental conditions in the main development region (MDR), or the region between $10^{\circ}$ and $20^{\circ} \mathrm{N}$ and the Central American and African coasts, have more traditionally been associated with North Atlantic hurricane activity than the region of central interest here, we have included an analysis of SST variability in the MDR. Results show that processes similar to those described in the WAC region are responsible for the majority of the 2006 minus 2005 SST difference in the MDR, although in the MDR there is some evidence that effects of ocean current variability play an important role.

\section{Model and data}

The ocean model used here is a one-dimensional mixed layer model that was previously used to predict SST and surface velocity variations in the Sargasso Sea (Price et al. 1986). It has been used in many studies of midocean SST variability, including the recent study of the tropical and subtropical Indian Ocean (Chiodi and Harrison 2006, 2007). This is a now-classic model that predicts deepening of the mixed layer when the water 
column becomes either statically or dynamically unstable and predicts shoaling of the mixed layer under suitably strong addition of buoyancy to the upper layers. Dynamic stability is based on a specified critical value of the bulk Richardson number. A critical value of 0.65 is used here in accordance with Price et al. (1978, 1986). Runs were started in January from the World Ocean Atlas 2001 (Conkright et al. 2002) annual mean temperature and salinity profiles. Experiments have shown that the results are insensitive to initial conditions as long as the initial temperature and salinity values are reasonable. Standard runs are integrated using daily mean fluxes and a 15-min model time step. Applied daily mean fluxes are linearly interpolated to the model time step. Solar radiation is attenuated with depth within the water column by assuming a Jerlov type 1A (the vertical extinction coefficient is $20 \mathrm{~m}$ for $38 \%$ and $0.6 \mathrm{~m}$ for $62 \%$ of the insolation) water mass. This water type is appropriate for relatively clear tropical and subtropical waters. A small $\left(2 \times 10^{-5} \mathrm{~m}^{2} \mathrm{~s}^{-1}\right)$ background diffusion was applied uniformly to the water column to simulate the effects of unresolved processes, such as internal wave breaking [as was done in Chiodi and Harrison (2006, 2007)].

Daily average latent heat, sensible heat, longwave, shortwave, freshwater, and momentum fluxes from the NCEP-NCAR reanalysis project were used to integrate the model described above. [These fluxes are provided by the National Oceanic and Atmospheric Administration (NOAA)/Oceanic and Atmospheric Research (OAR)/Earth System Research Laboratory (ESRL) Physical Sciences Division (PSD), and they are available online at http://www.cdc.noaa.gov/cdc/reanalysis/ reanalysis.shtml.] The convention used here is nominally that upward (out of ocean) heat flux components are positive, but it is helpful to note that the sign is flipped in the figures herein to aid visual comparison with SST variability.

Atmospheric dust loading is not considered when shortwave radiation is calculated in the reanalysis (W. Ebisuzaki 2007, personal communication). Thus, the dust shielding effect discussed by Lau and Kim (2007) does not directly affect the solar forcing used in the experiments described below.

An array of 1D models, integrated with daily average surface fluxes, was used to re-create SST variability over the WAC region $\left(15^{\circ}-30^{\circ} \mathrm{N}, 70^{\circ}-40^{\circ} \mathrm{W}\right)$ and MDR (see Fig. 1). The western edge of the MDR was set at $84^{\circ} \mathrm{W}$ to prevent the highly variable eastern equatorial Pacific from influencing results. The roughly $2^{\circ} \times 2^{\circ}$ NCEP-NCAR reanalysis grid used here corresponds to a $17 \times 9$ and $38 \times 6$ grid in the WAC region and MDR, respectively.
As discussed below, results of this study show that latent heat flux anomalies are fundamentally important to the SST anomalies considered here. To better diagnose the mechanism responsible, the normalized latent heat anomalies are decomposed into two parts following the method of Chiodi and Harrison (2007). Readers are referred to this work for a more detailed discussion than that given here. In this method, the normalized latent heat flux anomaly is split into parts driven by wind speed and by $\Delta q$ anomalies,

$$
Q^{*} \cong S^{*}+\Delta q^{*},
$$

where $Q$ is latent heat flux, $S$ is wind speed, $\Delta q$ is the surface specific humidity minus the low-level $(2 \mathrm{~m})$ atmospheric specific humidity, and the asterisk signifies that the daily average anomaly (e.g., $S^{\prime}$ ) has been divided by the linearly interpolated climatological monthly mean (e.g., $\langle S\rangle$ ), for example, $S^{*}=S^{\prime} /\langle S\rangle$. Results have shown this approximation to be sufficiently accurate for the analysis discussed here. Based on squared correlation coefficients, the vast majority (about $98 \%$ ) of the variance in $Q^{*}$ is explained by the sum on the right-hand side of Eq. (1). All data necessary for this decomposition were obtained from NCEPNCAR reanalysis daily averages. Surface humidity was calculated from skin temperature, assuming that humidity is at saturation levels at the surface, and anomalies are defined as the daily average values minus the linearly interpolated monthly-mean climatology (base period 1992-2004).

The values of $\Delta q$, described above, along with the difference between low-level $(2 \mathrm{~m})$ air temperature and skin temperature $(\Delta T)$, were used to estimate the surface-to-boundary layer difference in enthalpy,

$$
\Delta k=C_{p} \Delta T L_{v} \Delta q,
$$

where $C_{p}$ is the heat capacity of air $\left(1.03 \times 10^{3} \mathrm{~J} \mathrm{~kg}^{-1}\right.$ $\left.\mathrm{K}^{-1}\right)$ and $L_{v}$ is the latent heat of evaporation $(2.25 \times$ $\left.10^{6} \mathrm{~J} \mathrm{~kg}^{-1}\right)$. The convention used here is that $\Delta$ represents the surface minus atmospheric variables.

Although net freshwater input can affect the evolution of ocean mixed layer depth in some cases, experiments have shown that the inclusion of the reanalysis net surface freshwater flux does not significantly affect the results described here and, therefore, will not be discussed.

The temperature tendency due to ocean heat flux convergence, the product of horizontal SST gradients $\left(\nabla_{h} \mathrm{SST}\right)$ and ocean surface current $(\mathbf{U})$,

$$
-\mathbf{U} \cdot \nabla_{h} \mathrm{SST},
$$

was determined using observed SST and two types of current estimates; the wind-driven component and cur- 
rents from an ocean data assimilation model [5-m depth currents from NCEP's Global Ocean Assimilation Data System (GODAS); data available online at http://iridl. ldeo.columbia.edu]. The wind-driven component was estimated using the Ekman theory, assuming wind stress is absorbed within the mixed layer. Mixed layer depths were determined by the model.

Two types of experiments were performed to better understand the ocean's response to the various components of surface heat and momentum flux. First, the effects of interannual surface flux anomalies were considered by replacing various daily average forcing components with their respective climatological values. For these runs, monthly average climatologies were computed using a 1992-2004 base period and then linearly interpolated to the model time resolution. This base period was chosen to maximize the benefits of recent satellite-based observations to the reanalysis and to exclude the years of interest here. In the case of momentum flux, care was taken so that the averaging procedure did not reduce the monthly average stress, as could be the case if the averaging was done to the zonal and meridional components separately.

A second set of experiments was performed to determine the effects of submonthly surface flux variability. This was done by removing submonthly variability from the surface fluxes using a 30-day running mean filter prior to integrating the model. Again, care was taken so that the filter did not reduce the magnitude of the wind stress on monthly and longer time scales. Differences between results from this set of experiments and the standard daily average runs described initially are, therefore, due to the effects of submonthly variability in the fluxes.

SST observations were obtained from the Tropical Rainfall Measuring Mission (TRMM) Microwave Imager (TMI). TMI data are produced by Remote Sensing Systems and sponsored by the National Aeronautics and Space Administration (NASA) Earth Science REASoN DISCOVER Project (data available online at www.remss.com). TMI data have a $0.25^{\circ} \times 0.25^{\circ}$ resolution between roughly $40^{\circ} \mathrm{N}$ and $40^{\circ} \mathrm{S}$, and have been shown to have sufficient accuracy (roughly $0.5^{\circ} \mathrm{C}$ random error on a given measurement in rain-free conditions; Wentz et al. 2000) for the analysis conducted here. The interval between repeated TMI SST measurements at a given geographic location is usually less than 2 days, although measurements often occur twice in 1 day. Here, the daily ascending and descending tracks are linearly filled in time and smoothed with a 7-day running mean filter prior to analysis. Submonthly SST variability is identified by high-pass filtering the
TMI data. This is accomplished here by subtracting 30 day running mean filter data from the original 7-day running mean filtered data.

Monthly average Emanuel (1995) potential intensity was calculated from NCEP-NCAR atmospheric profiles and skin temperature using code available from Emanuel's Web site.

\section{Results}

Much of the seasonal and higher-frequency WAC SST variability for both years considered is reproduced by the model used here (Fig. 2a). For example, in 2006 (blue curve) both the model and observed SST begin to warm in April and steadily increase until the first week of June, after which time SST stays relatively constant until about August when a relatively sharp rise (a tendency of about $2^{\circ} \mathrm{C}$ per month) occurs. This rise in SST reversed the cold anomaly that developed when SST stayed flat during July. SST then begins to decrease near the beginning of September, more or less following the climatological trajectory. Model results in the WAC region reproduce observed 2005 SST variability with a similarly high fidelity (Fig. 2a, red curve.)

In both years, the WAC area-averaged SST curves are punctuated by peaks that have amplitudes of $0.5^{\circ}-$ $1.0^{\circ} \mathrm{C}$ relative to background levels and time scales of about a week or two (e.g., SST maxima in Fig. 2a, near the end of April 2005, end of May 2005, and latter half of June 2005). Analogs of these features with similar amplitude and timing are also seen in the model results. We will refer to these events as abrupt warming events because they appear to rise above background levels for relatively short periods. Temperature tendencies during the formation stages of the abrupt warming events are significantly greater than those seen in the mean seasonal cycle (dashed line in Fig. 2a). For example, WAC SST was observed to rise more than $1^{\circ} \mathrm{C}$ from 10 to 17 June, although the climatological expectation is only about $0.2^{\circ} \mathrm{C}$. Though warming events are apparent in both years in the WAC region, the amplitudes of the larger 2005 events (marked by arrows in Fig. 2a) are greater than any seen in 2006. A large abrupt warming event can also be seen in the MDR, in both the model and observations, near the end of May 2005 (marked by an arrow in Fig. 2b).

The model results have some shortcomings that can be the result of errors in the fluxes or model physics. For example, the model greatly overpredicts the amplitude of the mid-June 2005 warming event. The model also fails to warm sufficiently during July compared with observations, although, because a similar bias is evident in 2006, the model predicts a 2006 minus 2005 
a) Western Atlantic and Caribbean SST $\left(70^{\circ} \mathrm{W}-40^{\circ} \mathrm{W}, 15^{\circ} \mathrm{N}-30^{\circ} \mathrm{N}\right)$

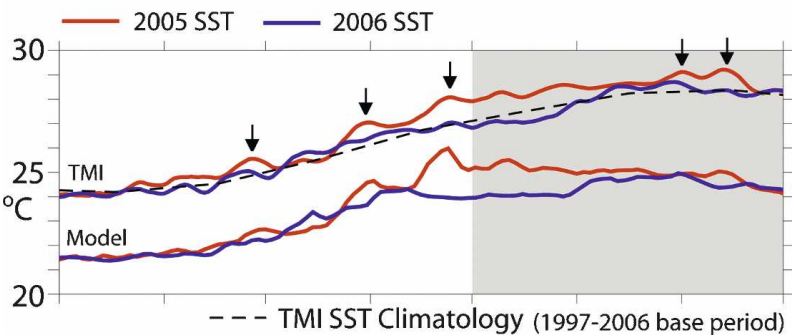

c) SST Difference

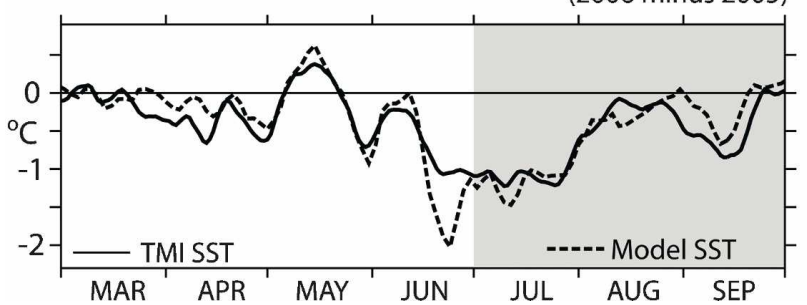

b) Main Development Region SST

$\left(84^{\circ} \mathrm{W}-15^{\circ} \mathrm{W}, 10^{\circ} \mathrm{N}-20^{\circ} \mathrm{N}\right)$

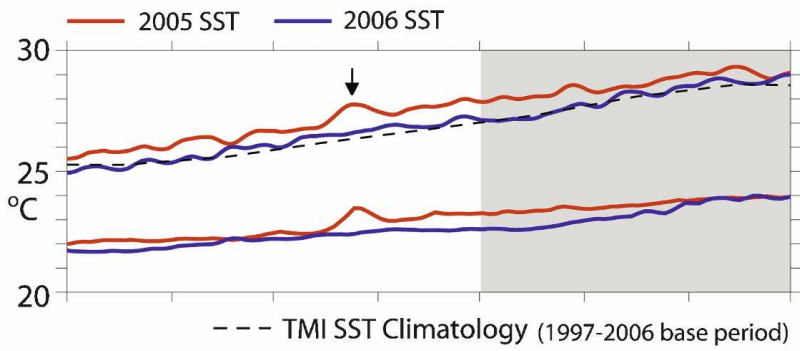

d) SST Difference

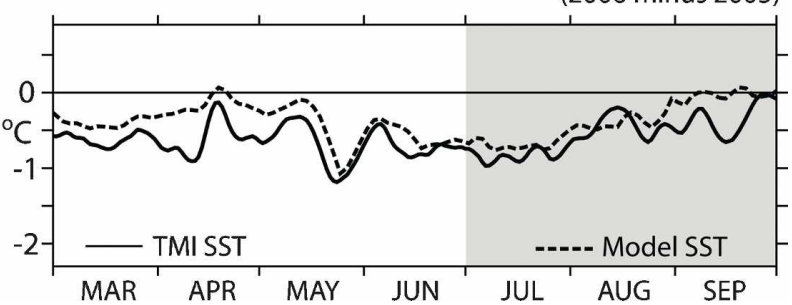

FIG. 2. (a) WAC area-averaged TMI SST during 2005 (red curves) and 2006 (blue curves). Model results are offset low for clarity. Arrows point to 2005 abrupt warming events discussed in the text. (b) Same as (a), but for the MDR. (c) Difference between the 2006 and 2005 area-averaged SST curves shown in (a) for observations (solid curve) and model (dashed curve). (d) Same as (c), but for the MDR.

difference in SST (discussed below) that remains remarkably close to the observations. Accordingly, we find this simple model adequate for the analysis below.

Considering the possible level of error in the reanalysis surface fluxes, the observed difference between 2006 and 2005 WAC area-averaged SST is remarkably well reproduced in the model. Both monthly and submonthly scale variations are reasonably well reproduced by the model (Fig. 2c). The correlation between model and TMI area-averaged SST is 0.89 over the March-September interval considered here and also 0.89 over the JAS interval (noted by shading in Fig. 2). Based on zero crossings of the autocovariance of the modeled and observed data, we estimate 15 and 8 degrees of freedom for these intervals, respectively. Thus, the correlations are significant at the $95 \%$ confidence interval (by Fisher's $z$ transform).

Averaged spatially over the WAC region and temporally over JAS, the observed 2006 minus 2005 SST difference $\left(-0.61^{\circ} \mathrm{C}\right)$ is well reproduced by the model $\left(-0.55^{\circ} \mathrm{C}\right)$. Because the solar forcing used here does not depend on atmospheric dust loading, this suggests that dust loading effects are not a primary cause of the observed SST difference, as hypothesized by Lau and Kim (2007).

We find that the 2006 minus 2005 MDR areaaveraged SST is also reasonably well reproduced by our model (Fig. 2d). The correlation between model and observed area-averaged MDR SST difference is high, though it is slightly lower than for the WAC region (0.75 for the period shown in Fig. 2d).

Although generally good, the model results have some significant errors. In JAS, the largest model discrepancies occur in late August and September for both regions, with the model underpredicting the observed 2006 minus 2005 SST difference. We attribute this model discrepancy in the WAC region partly to the inability of the model to adequately reproduce the abrupt warming event observed on 1 September 2005.

There is some evidence that ocean currents are important to the MDR 2006 minus 2005 SST difference. When integrated from the beginning of the calendar year, the advective temperature tendency based on GODAS 5-m depth currents accounts for a 2006 minus 2005 MDR SST difference of about $-0.3^{\circ} \mathrm{C}$ averaged spatially and over JAS. This is on the order of the model bias seen in Fig. $2 \mathrm{~d}$ at this time (about $0.2^{\circ} \mathrm{C}$ ), and it suggests that this process must be considered to fully understand SST variability in the MDR. When wind-driven currents are used, however, ocean advection only accounts for a difference of about $-0.1^{\circ} \mathrm{C}$, suggesting that other (e.g., geostrophic) components are mainly responsible for this difference.

In the WAC region, both current estimates considered accounted for only relatively small (usually $<0.1^{\circ} \mathrm{C}$ magnitude) changes. This is consistent with in situ heat balance studies in or near the WAC region that have found the effects of ocean currents to be of 

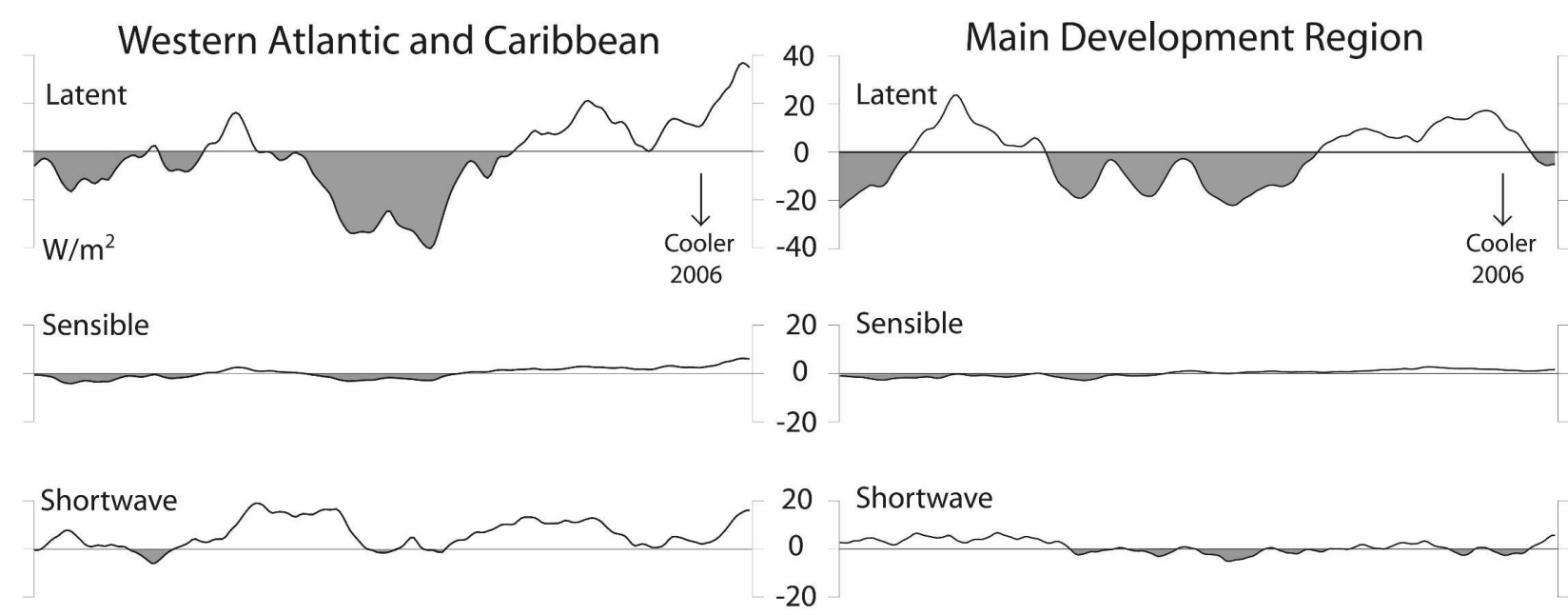

Longwave

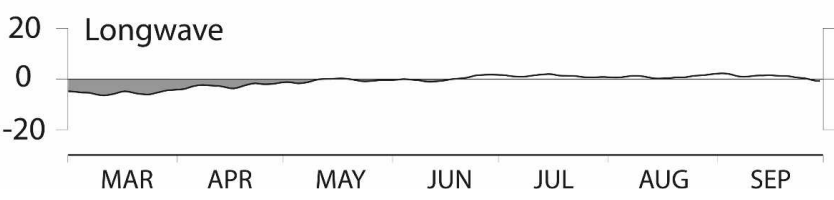

FIG. 3. (left) The year-to-year difference of WAC area-averaged net surface heat flux components. A 30-day running mean filter has been applied to the data. The sign convention has been reversed with respect to the text so that negative differences (shaded) tend to cool 2006 relative to 2005. (right) Same as (left), but for the MDR.

secondary importance to the upper layer heat balance (Foltz and McPhaden 2005; Halliwell and Cornillon 1990).

Inspection of the 2006 minus 2005 WAC areaaveraged heat flux components (see Fig. 3, left; the sign is reversed to aid visual comparison with the plots of SST described above) shows that only latent heat flux difference has the amplitude and timing necessary to account for much of the observed average SST difference. For about a month prior to JAS, roughly $30 \mathrm{~W}$ $\mathrm{m}^{-2}$ more latent heat was lost from the surface in 2006 than in 2005. In comparison, longwave radiation and sensible heat flux have amplitudes that are too small to matter much over the time scales considered here $(<5$ $\mathrm{W} \mathrm{m}^{-2}$ ), although longwave radiation is consistently larger in 2006 and likely accounts for some of the observed SST difference. Although shortwave forcing amplitudes are a bit larger (often $15-20 \mathrm{~W} \mathrm{~m}^{-2}$ ) than those of longwave and sensible heat flux, they tend to warm the surface more in 2006 than in 2005, and thus they damp the observed SST difference. This suggests that the observed SST difference is primarily due to latent heat flux forcing.

Although both the observations and (to a somewhat lesser extent) the model results, averaged over the WAC region, show late season (mid-August through September) 2006 to be significantly cooler than late season 2005 , it is notable that there is no obvious reason apparent in the fluxes shown in Fig. 3; only longwave radiation shows a relatively weak $\left(<5 \mathrm{~W} \mathrm{~m}^{-2}\right)$ tendency for relative cooling in September 2006, whereas each of the other heat flux terms shows a larger tendency for relative warming in September 2006. We will discuss reasons for this late-season 2005 warming below.

Examination of the 2006 minus 2005 components of surface heat flux averaged over the MDR (Fig. 3, right) shows that latent heat flux is the most important component in both regions.

To better understand the latent heat flux differences shown in Fig. 3, we decomposed the latent heat flux anomaly from each year into parts dependent solely on wind speed and $\Delta q$ (Fig. 4, red and blue curves, respectively; signs have been reversed to match Fig. 3.) Inspection of these terms in the WAC region shows that stronger winds in 2006 account for the stronger surface latent heat loss observed from mid-May 2006 through mid-July 2006 (Fig. 4a). This mechanism was previously suggested to be important by Lau and Kim (2007). During this time in 2006, there were also stronger winds driving stronger surface latent heat loss over the MDR (Fig. 4b).

To examine the relationship between the anomaly components discussed above and the environmental conditions important to hurricane intensity, we have included plots of 2006 minus 2005 differences of $\Delta k$ in 
a) Western Atlantic and Caribbean

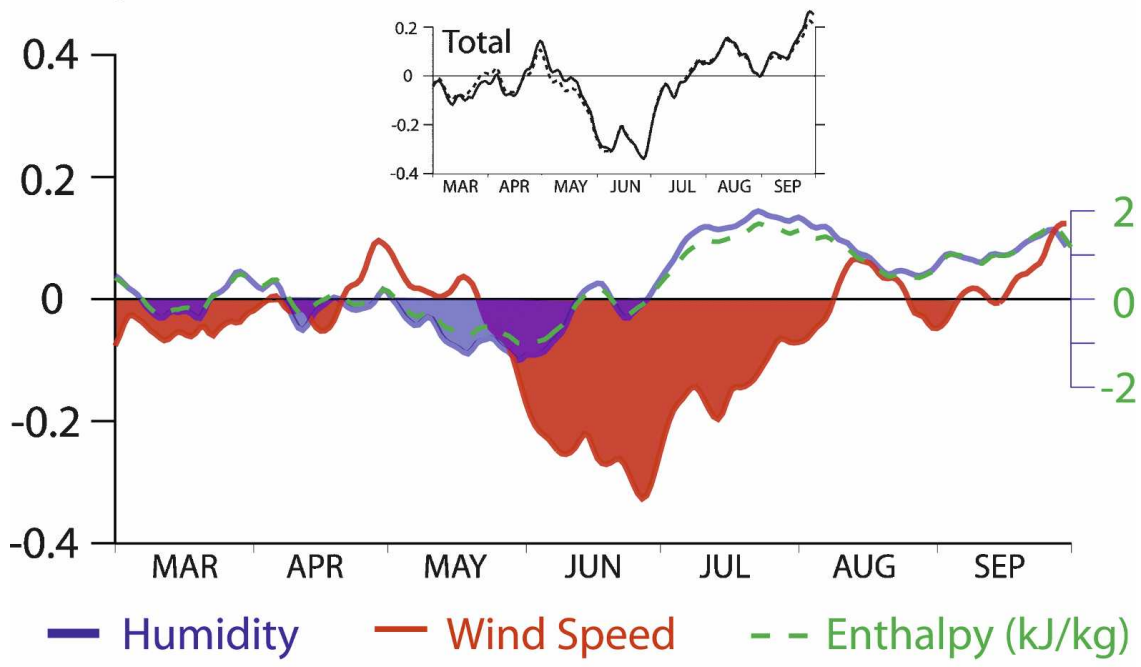

\section{b) Main Development Region}

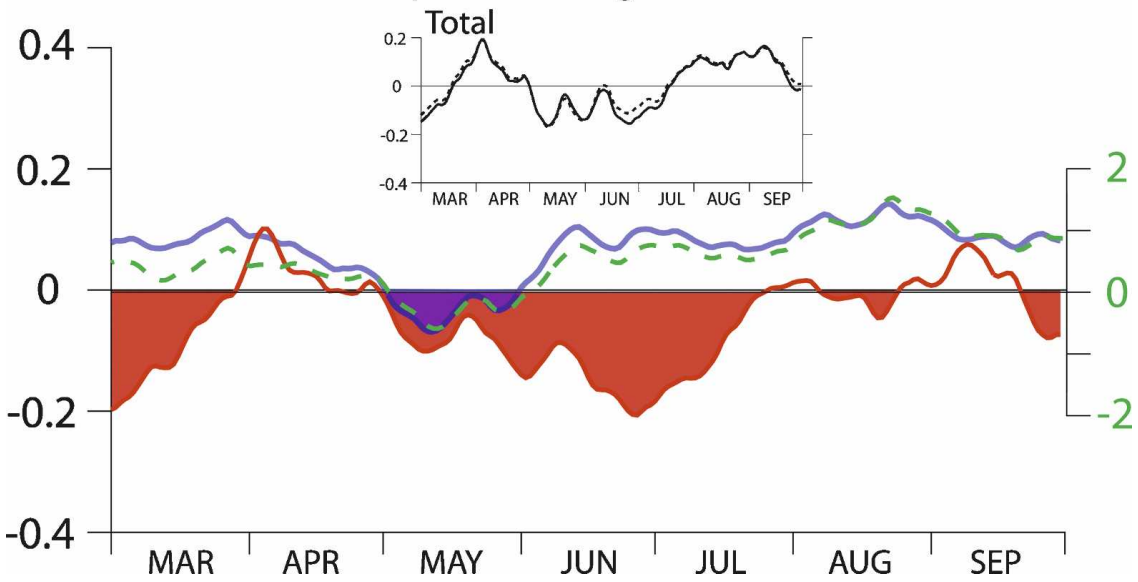

FIG. 4. (a) The normalized and WAC area-averaged 2006 minus $2005 S^{*}$ (red curve) and $\Delta q^{*}$ (blue curve) differences. Curves are drawn with shading indicating differences that tend to cool (2006 relative to 2005). The dashed green curve is the WAC area-averaged 2006 minus $2005-\Delta k$. (Positive values indicate a larger surface-boundary layer difference in enthalpy in 2005.) The inset shows the normalized and area-averaged 2006 minus 2005 latent heat flux difference [ $Q^{*}$ from Eq. (1), solid curve] and the sum of the 2006 minus $2005 S^{*}$ and $\Delta q^{*}$ differences (dashed curve). (b) Same as (a), but for the MDR.

Fig. 3 (dashed green curves). It is apparent that $\Delta k$ variability is closely related to $\Delta q$ variability in both regions (correlations of 2006 minus 2005 differences are 0.99 and 0.92 for the WAC region and MDR, respectively). This relationship occurs because the $\Delta q$ term in Eq. (2) has a larger (3-4 times) standard deviation than the $\Delta T$ term and because $\Delta T$ is correlated with $\Delta q$ (correlations are 0.79 and 0.72 for the WAC region and MDR, respectively).

This suggests that in both regions considered, $\Delta k$ conditions were more conducive to the formation of intense hurricanes in JAS 2005 than in JAS 2006 mainly because $\Delta q$ was larger during 2005. Thus, the manner in which latent heat flux variability arises is important to the relationship between SST and $\Delta k$; if SST variability was driven by $\Delta q$ effects, warm SST would likely be associated with small values of $\Delta k$.

Because the stronger wind speeds seen in 2006 can also cause relatively cooler SST through increased wind mixing, the relative effects of heat and momentum fluxes in the 2006 minus 2005 average SST remain to be determined. To compare the effects of these two types of surface flux, two sets of experiments were conducted. First, daily average wind stress was replaced by its cli- 


\section{a) Western Atlantic and Caribbean}

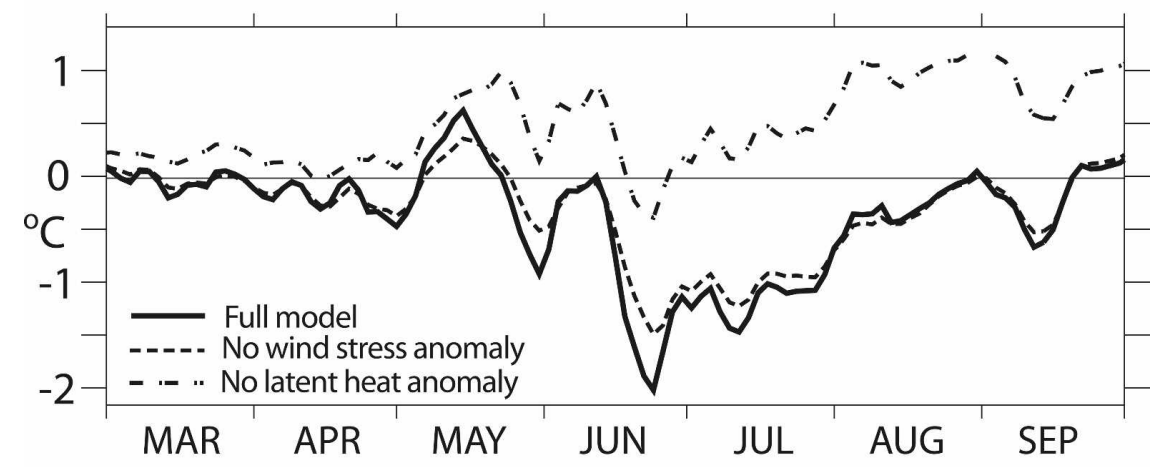

\section{b) Main Development Region}

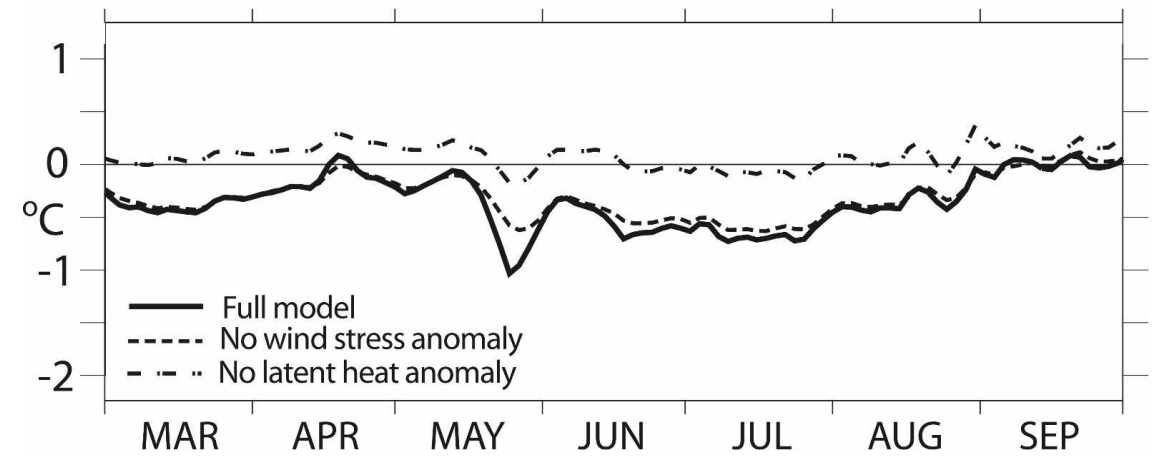

FIG. 5. (a) Model WAC area-averaged 2006 minus 2005 SST difference (solid curve) and model results with latent heat flux anomalies removed (dotted-dashed curve) and wind speed anomalies removed (dashed curve). (b) Same as (a), but for the MDR.

matology (so that variations in wind mixing did not contribute to the 2006 minus 2005 SST difference). Second, the daily average latent heat fluxes were replaced by their monthly-mean climatology (so that heat flux anomalies did not contribute to the 2006 minus 2005 SST difference). The original integrations provide the control runs in this case. The close agreement between the first set of runs and the original result (cf. solid and dashed curves in Figs. 5a,b) shows that wind mixing does not play a significant role, hence the average model SST difference between years is mainly caused by the effects of wind speed on latent heat flux. This is confirmed by the results of the second set of runs (dashed-dotted curves in Figs. 5a,b), which predict that 2006 would have been warmer than 2005 in JAS were it not for the latent heat flux anomalies. Note that when latent heat flux anomalies are removed, the results follow the trends seen in the solar forcing, which, according to the data used here, acts to damp the observed SST difference (cf. Figs. 3, 5).

We now address the cause of the late-season (midAugust-September) difference in SST. As discussed above, there is no indication from the surface fluxes shown in Fig. 3 that late-season 2005 would be warmer than 2006. What, then, causes the relative warmth in September 2005? Some insight is provided by a set of experiments in which submonthly variability was removed from the daily average fluxes by smoothing them with a 30-day running mean filter prior to integration. Note that, in these experiments, both the daily average and smoothed flux runs transfer about the same amount of heat and momentum across the air-sea interface over monthly or longer time scales. Monthlymean (or longer) differences between these integrations are, therefore, the result of the ocean's nonlinear response to submonthly forcing. This response has previously been shown to bias SST toward warmer values in the summer in the subtropics (Chiodi and Harrison 2006).

Results show that when the smoothed fluxes are integrated into the model, the abrupt warming events (e.g., peaks in SST are around 1 and 20 June, and 13 September 2005) are no longer apparent. Importantly, comparison of these two runs shows that the net effect of the warming events, which are more prevalent in 2005 than in 2006, results in an additional warming of 


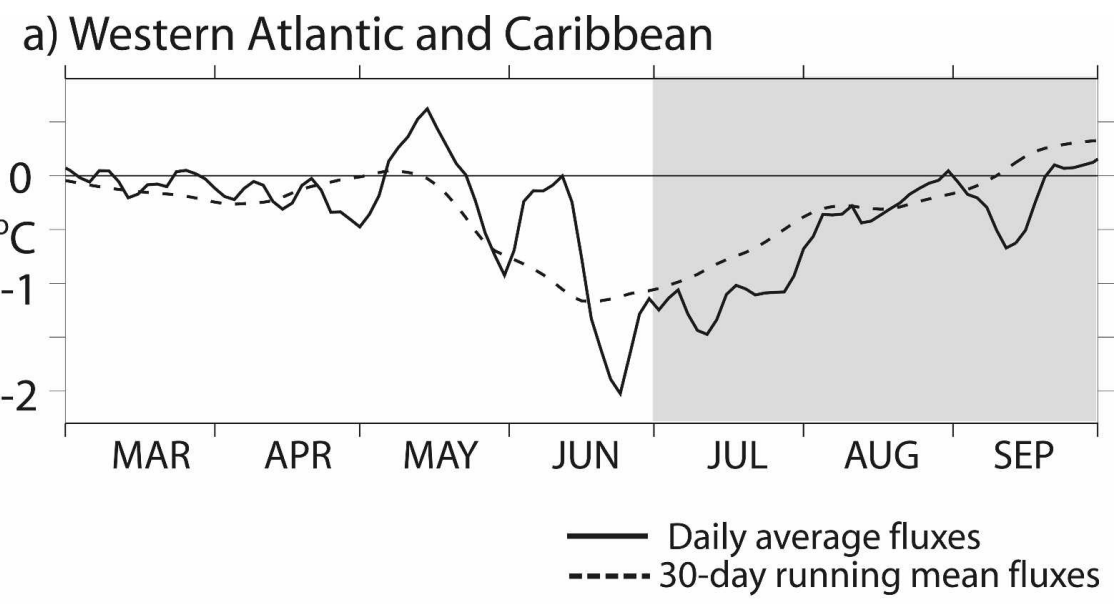

b) Main Development Region

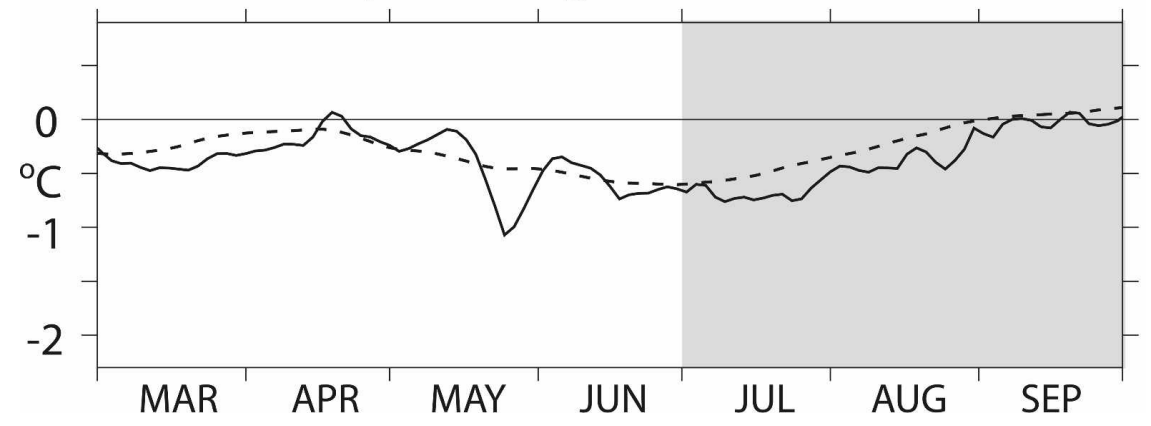

FIG. 6. (a) WAC area-averaged 2006 minus 2005 SST from integration of daily average fluxes (solid curve) and 30-day running mean smoothed fluxes (dashed curve). (b) Same as (a), but for the MDR.

$0.23^{\circ} \mathrm{C}$ in JAS 2005 , relative to JAS 2006 , averaged over the WAC region (Fig. 6a). This effect accounts for $43 \%$ of the JAS model SST difference and more than $90 \%$ of the late-season difference. This effect is also significant in the MDR (see Fig. 6b) where it accounts for an additional $0.16^{\circ} \mathrm{C}$ of 2005 warming, averaged spatially and temporally in JAS. This is also $43 \%$ of the 2006 minus 2005 JAS warming reproduced by the daily average flux runs.

The spatial structure of the abrupt warming events may be observed in snapshots of high-passed SST. For example, it is evident that abrupt warming (high-passed SST $>0.5^{\circ} \mathrm{C}$ ) occurred over most of the WAC region around 13 September 2005 (Fig. 7a) and over most of the MDR near the end of May 2005 (Fig. 7b). Analogs of these events were reproduced in the model on these days (Figs. 7c,d). The analogs have spatial patterns and amplitudes that are roughly similar to those in the TMI data (Fig. 7).

Inspection has shown that the model reproduces events at each of the SST peaks highlighted by arrows in Figs. 2a,b (snapshots not shown for brevity), though not always with the degree of fidelity seen in Fig. 7. For example, the model fails to adequately reproduce the spatial scale and amplitude of the event observed around 2 September 2005. It is likely that the failure of the model to fully reproduce the scale and intensity of this event explains some of the late-season model bias toward nearly equal temperature in September 2005 and 2006.

The atmospheric conditions and ocean physics involved in the formation of these events have been previously described by Chiodi and Harrison (2006), who found that these events are usually associated with lowwind-speed and high-humidity conditions that are prevalent near the center of atmospheric anticyclones. Readers are referred to this work for a more detailed discussion of the formation mechanism.

There is evidence that the mean atmospheric conditions prevalent in the WAC region during the formation stages of the abrupt warming events and the longer-term rise in area-averaged SST during June 2005 are similar to those typically conducive to anomalously low winds. To characterize the usual conditions associated with significant wind anomalies in the WAC region, absolute NCEP-NCAR SLP and wind speed 


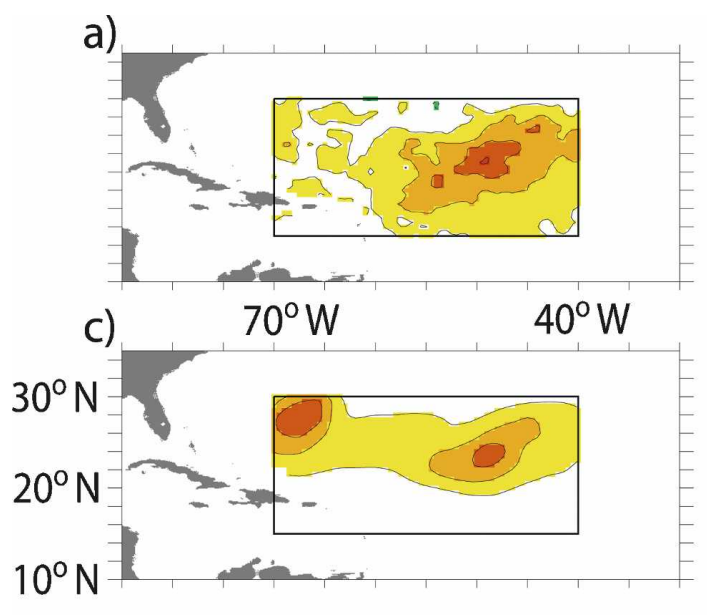

b)
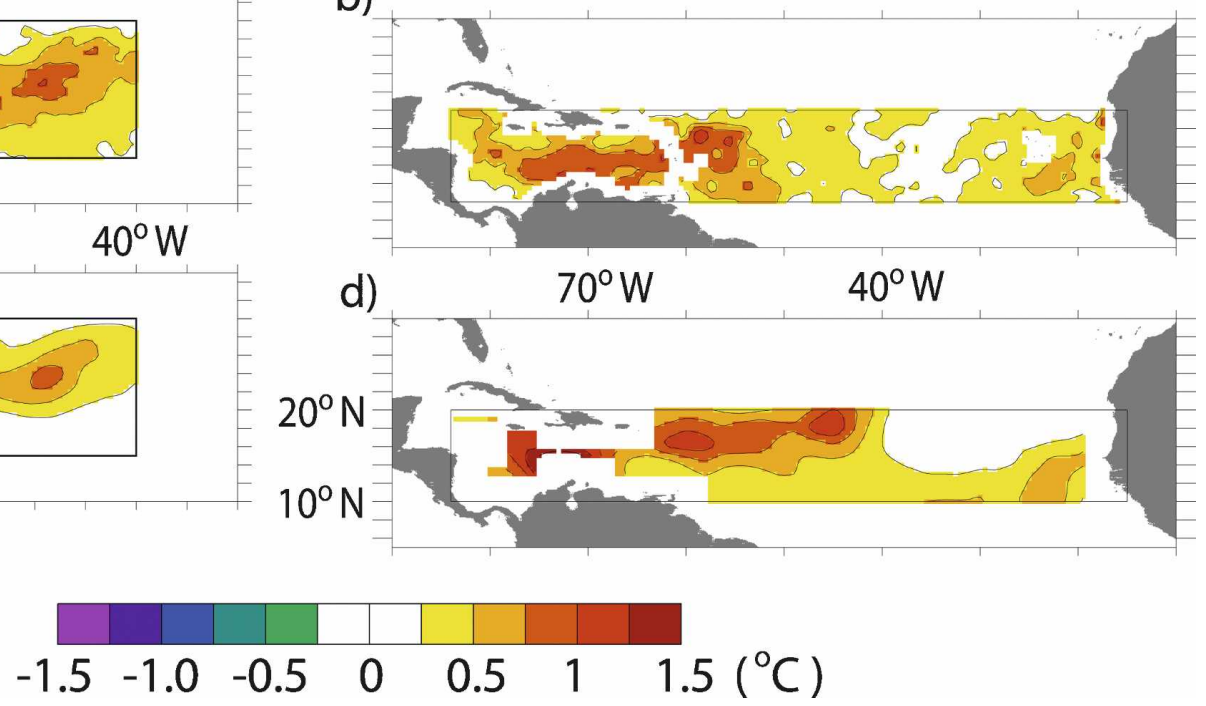

FIG. 7. Snapshots of high-passed SST for (a) TMI data in the WAC region on 13 Sep 2005, (b) TMI data in the MDR on 25 May 2005, and (c) and (d) same as (a) and (b), respectively, but for model data.

anomaly composites were formed from an index based on the area-averaged daily mean wind speed in the WAC region. To form the high-wind (low wind) composite, daily average data were averaged over all days in which the area-averaged winds were above (below) one standard deviation. The period considered was 1992-2004.

In the high-wind composite, a strong and broad SLP maximum is seen over the North Atlantic, centered at roughly $35^{\circ} \mathrm{N}, 45^{\circ} \mathrm{W}$ (Fig. $8 \mathrm{a}$ ). In this case, there is a strong northward gradient in SLP over the WAC region. In the low wind speed case, the SLP maximum is displaced toward southern Europe and northern Africa, such that a broad region of low SLP and low SLP gradient lies over much of the western subtropics (Fig. $8 \mathrm{~b})$. This general scenario also holds for the periods of 2005 warming discussed above; the low-wind-speed periods (June 2005 and the first half of September 2005) in the WAC region show eastward-displaced SLP maxima (Figs. 8d,f) similar to the one seen in the lowwind-speed composite. Also, SLP fields averaged over the high-wind-speed periods (June 2006 and the first half of September 2006) bear a much stronger resemblance to the high-wind composite in and around the WAC region (Figs. 8c,e). The SLP anomalies shown in Fig. 8 bear some resemblance to patterns of SLP that have been previously found to covary with Atlantic SST on interannual time scales (Tourre et al. 1999).

Finally, we compare monthly-average 2006 minus 2005 differences in PI and SST averaged over the regions considered. These area-averaged differences are highly correlated over the calendar year (correlations are 0.69 and 0.87 for the WAC region and MDR, respectively) and also well correlated over the months considered here, including during hurricane season (Fig. 9). Note that the consistently negative SST differences (2005 warmer than 2006) correspond to negative PI differences (conditions more favorable for intense storms in 2005) for all months shown here, with the exception of March and April in the WAC region. It is also notable that both the largest PI and the largest or nearly largest SST differences occur in July in each region, although discrepancies between these variables (such as those seen in March for each region) show other variables must be important to PI variability.

\section{Discussion and summary}

Results presented here have shown that daily average surface fluxes from the NCEP-NCAR reanalysis can be integrated into a classic one-dimensional ocean mixed layer model to accurately reproduce the observed JAS 2006 minus JAS 2005 area-averaged SST difference in two regions thought to be important to hurricane activity. Experiments suggest that latent heat flux variability, caused by wind speed variability, causes a little more than half of the SST difference observed in the WAC region. Interestingly, though, a second set of experiments shows that the submonthly variability resolved by the NCEP-NCAR fluxes accounts for slightly more than $40 \%$ of the total WAC JAS SST difference and almost all of the September difference in the WAC 


\section{a) High Wind Speed Composite}

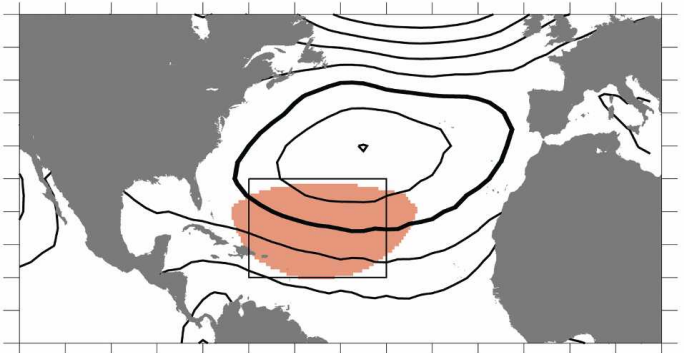

c)

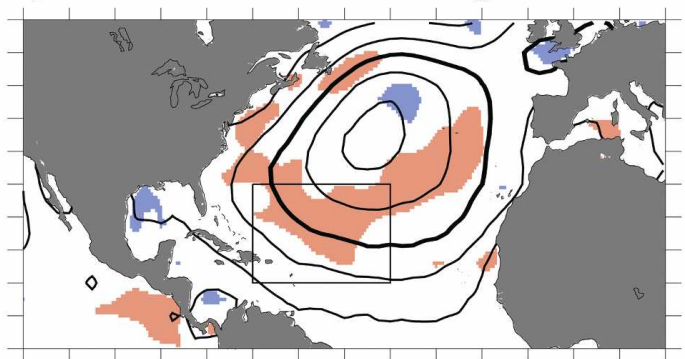

e) 1 Sep 2006 - 15 Sep 2006 Average

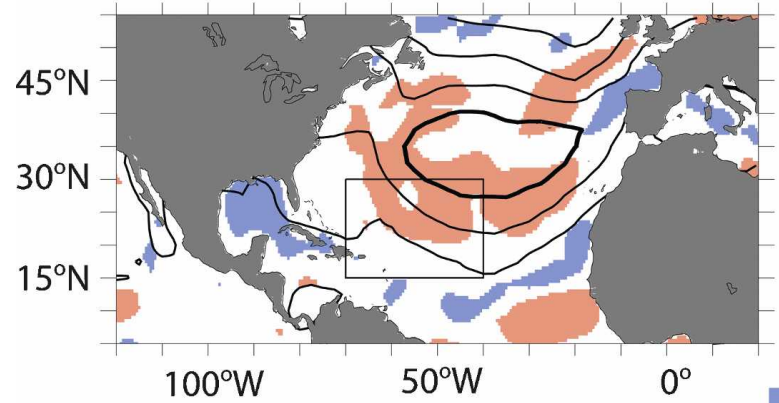

b) Low Wind Speed Composite

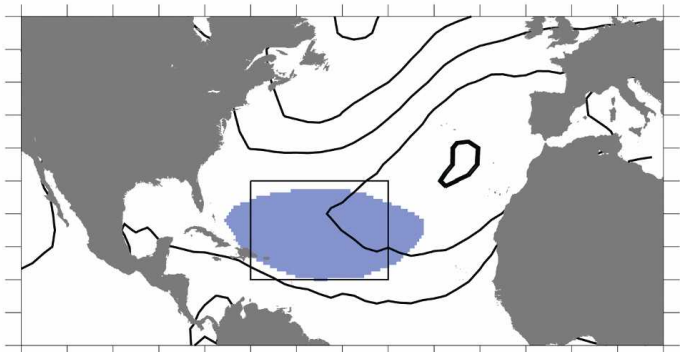

d)

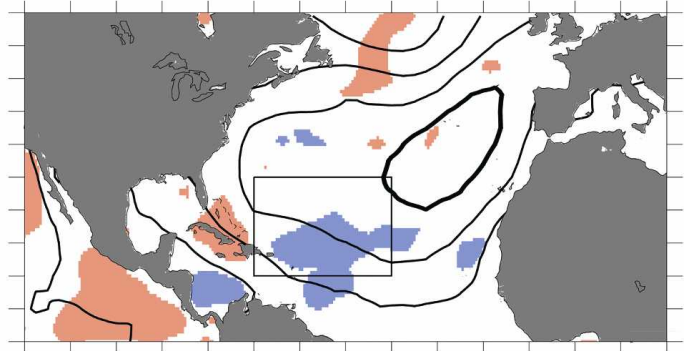

\section{f) 1 Sep 2005 - 15 Sep 2005 Average}

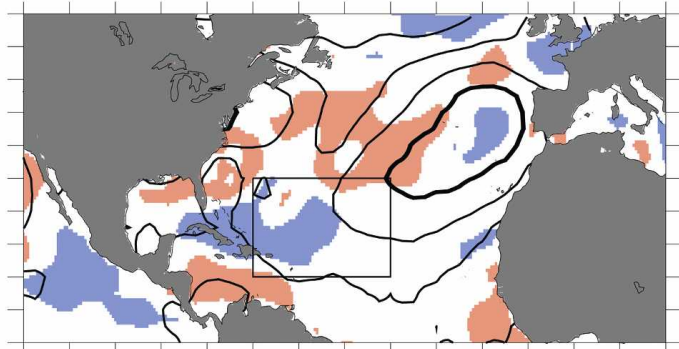

\section{Low Wind Anomaly Contours are NCEP SLP High Wind Anomaly}

FIG. 8. Composite mean SLP (contours) and wind speed anomaly (color field) in the WAC region. The contour interval is 300 and the $102000 \mathrm{~Pa}$ contour is dark. (a) Composite average for high-wind conditions ( $>1 \mathrm{std}$ dev) in the WAC region. Wind speed anomaly exceeding 1 std dev $\left(\sim 1.1 \mathrm{~m} \mathrm{~s}^{-1}\right)$ is shown. (b) Same as (a), but for the low-wind ( $<-1 \mathrm{std}$ dev) composite. (c)-(f) Averages over the time intervals listed in the figure. Wind speed anomaly is shown where it exceeds 0.5 std dev.

region. Thus, it may be said that the combination of lower average wind speed in 2006 and the prevalence of abrupt warming events in 2005 together explain the vast majority of the 2006 minus 2005 SST difference in the WAC region. These processes, along with the effects of ocean currents, can also account for most of the SST difference observed in the MDR.

The mechanism responsible for most of the SST difference in the WAC region, latent heat flux variability driven by wind speed variability, was previously suggested by Lau and Kim (2007) to be secondary in importance to solar shielding by atmospheric dust loading. Contrary to this preliminary hypothesis, results shown here strongly suggest that dust shielding of solar radia- tion plays a secondary role, at best, in driving these SST anomalies. The evidence for this is that the observed SST anomalies are reproduced well without direct consideration of dust shielding and that the solar forcing used in our experiments damps the observed SST difference at the average level of about $6 \mathrm{~W} \mathrm{~m}^{-2}$, which is likely more than the dust shielding effect can account for. Foltz and McPhaden (2008) provide interested readers with a complementary analysis of the relative effects of dust shielding and latent heat flux variability on tropical North Atlantic SST.

The result that is perhaps of greater interest here, however, is that, according to the model experiments described above, submonthly flux variations driven pri- 
a) Western Atlantic and Caribbean

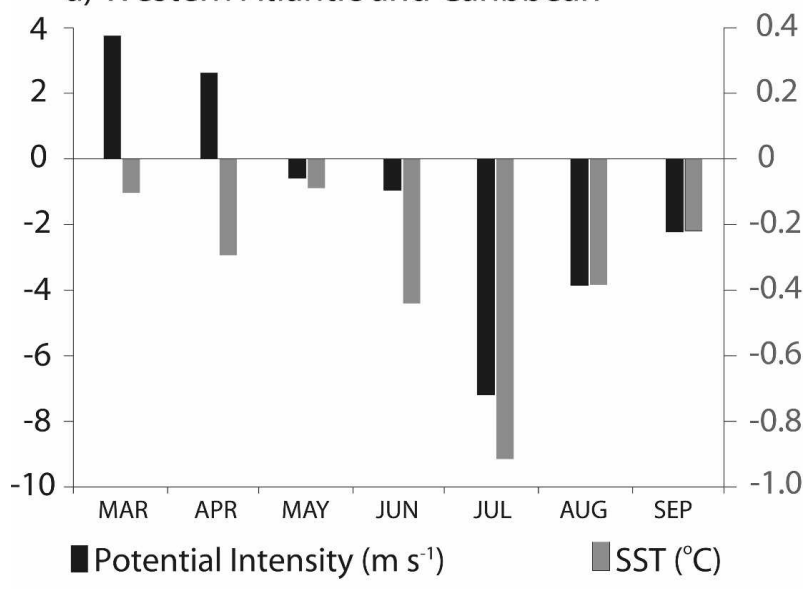

b) Main Development Region

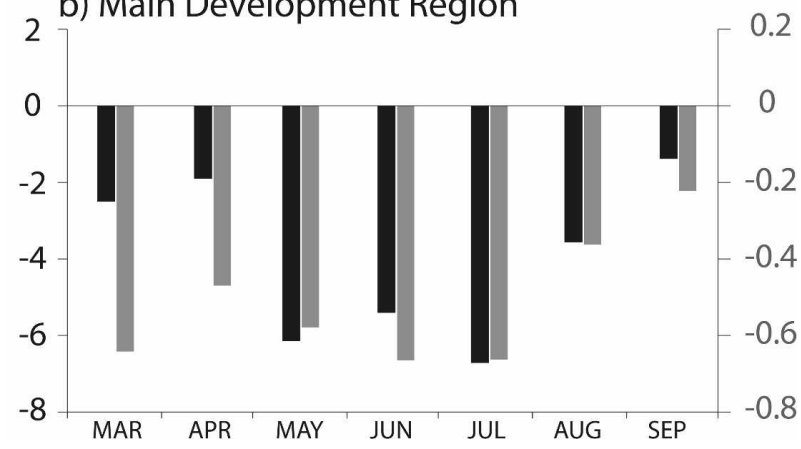

FIG. 9. (a) WAC area and monthly averaged 2006 minus 2005 SST (gray bars) and PI (black bars). (b) Same as (a), but for the MDR.

marily by near synoptic-scale atmospheric phenomena caused a significant increase in SST during JAS 2005, relative to JAS 2006 in both the WAC region and MDR. SST anomalies driven by this mechanism may be especially relevant to hurricane prediction because their formation can imply that additional amounts of heat are fluxed from the ocean to the atmosphere compared to anomalies that are caused by longer-term airsea flux variability. This scenario is likely seen late season in the WAC region, where a warm anomaly forms in September 2005 (Fig. 2a) even though, on average, the surface heat flux anomaly during this time is directed out of the ocean (cf. Fig. 3a). In this respect, anomalies caused by this mechanism may couple to the atmosphere similarly to anomalies caused by solar radiation.

It may be, however, that these SST anomalies are of limited importance to mature storms because their development relies on the formation of relatively thin warm mixed layers, which may be quickly mixed to lower levels by the strong winds associated with tropical storms. More research is needed to better understand the relationship between these types of SST anomalies and hurricane formation.

To the extent that the submonthly flux-driven SST anomalies are significant to hurricane activity, the results presented here show that submonthly atmospheric variability will need to be predicted or parameterized to obtain accurate hurricane forecasts. This presents somewhat of a break with the traditional paradigm of climate prediction, in which estimates of future mean atmospheric conditions are used to forecast the future. This also challenges us to better understand the physical controls of this class of atmospheric variability.

The reasonably close relationship between potential intensity and SST described here supports Lau and Kim's (2007) argument that SST variability was an important factor in causing the stark contrast in hurricane activity between the 2005 and 2006 North Atlantic hurricane seasons. We leave a more detailed analysis of the relationship between potential intensity and SST during these seasons for further study.

Acknowledgments. This paper benefited from helpful reviews from two anonymous reviewers and Kerry Emanuel. We are grateful to G. A. Vecchi, who graciously provided the potential intensity data used in this study and offered helpful commentary. This publication is partially funded by the Joint Institute for the Study of the Atmosphere and Ocean (JISAO) under NOAA (Cooperative Agreement NA17RJ1232).

\section{REFERENCES}

Bender, M. A., and I. Ginis, 2000: Real-case simulations of hurricane-ocean interaction using a high-resolution coupled model: Effects on hurricane intensity. Mon. Wea. Rev., 128, 917-946.

Brennan, J. F., 1935: Relation of May-June weather conditions in Jamaica to the Caribbean tropical disturbances of the following season. Mon. Wea. Rev., 63, 13-14.

Chiodi, A. M., and D. E. Harrison, 2006: Summertime subtropical sea surface temperature variability. Geophys. Res. Lett., 33, L08601, doi:10.1029/2005GL024524.

— southern Indian Ocean sea surface temperature variability: On the importance of humidity anomalies and the meridional advection of water vapor. J. Climate, 20, 4835-4852.

Conkright, M. E., and Coauthors, 2002: Introduction. Vol. 1, World Ocean Database 2001, NOAA Atlas NESDIS 42, 167 pp.

Emanuel, K., 1995: Sensitivity of tropical cyclones to surface exchange coefficients and a revised steady-state model incorporating eye dynamics. J. Atmos. Sci., 52, 3969-3976.

- 2000: A statistical analysis of tropical cyclone intensity. Mon. Wea. Rev., 128, 1139-1152.

, 2003: Tropical cyclones. Annu. Rev. Earth Planet. Sci., 31, 75-104. 
- 2005: Increasing destructiveness of tropical cyclones over the past 30 years. Nature, 436, 686-688.

Foltz, G. R., and M. J. McPhaden, 2005: Mixed layer heat balance on intraseasonal time scales in the northwestern tropical Atlantic Ocean. J. Climate, 18, 4168-4184.

$\longrightarrow$, and — 2008: Impact of Saharan dust on tropical North Atlantic SST. J. Climate, 21, 5048-5060.

Goldenberg, S. B., and L. J. Shapiro, 1996: Physical mechanisms for the association of El Niño and West African rainfall with Atlantic major hurricane activity. J. Climate, 9, 1169-1187.

Halliwell, G. R., Jr. and P. Cornillon, 1990: Large-scale SST variability in the western North Atlantic subtropical convergence zone during FASINEX. Part II: Upper ocean heat balance and frontogenesis. J. Phys. Oceanogr., 20, 223-234.

Holland, G. J., 1997: The maximum potential intensity of tropical cyclones. J. Atmos. Sci., 54, 2519-2541.

Hoyos, C. D., P. A. Agudelo, P. Webster, and J. A. Curry, 2006: Deconvolution of the factors contributing to the increase in global hurricane intensity. Science, 312, 94-97.

Kimberlain, T. B., and J. B. Elsner, 1998: The 1995 and 1996 North Atlantic hurricane seasons: A return of the tropicalonly hurricane. J. Climate, 11, 2062-2069.

Landsea, C., and W. M. Gray, 1992: The strong association between western Sahelian monsoon rainfall and intense Atlantic hurricanes. J. Climate, 5, 435-453.

— R. A. Pielke Jr., A. M. Mestas-Nuñez, and J. A. Knaff, 1999: Atlantic basin hurricanes: Indices of climatic changes. $\mathrm{Cli}$ mate Change, 42, 89-129.

Lau, W. K. M., and K.-M. Kim, 2007: How nature foiled the 2006 hurricane forecasts. EOS, Trans. Amer. Geophys. Union, $\mathbf{8 8}$ 105-107.

Miller, B., 1958: On the maximum intensity of hurricanes. J. Meteor., 15, 184-195.
Molinari, R. L., and A. M. Mestas-Nuñez, 2003: North Atlantic decadal variability and the formation of tropical storms and hurricanes. Geophys. Res. Lett., 30, 1541, doi:10.1029/ 2002GL016462.

Price, J. F., C. N. K. Mooers, and J. C. Van Leer, 1978: Observation and simulation of storm-induced mixed-layer deepening. J. Phys. Oceanogr., 8, 582-599.

$\longrightarrow$, R. A. Weller, and R. Pinkel, 1986: Diurnal cycling: Observations and models of the upper ocean response to diurnal heating, cooling, and wind mixing. J. Geophys. Res., 91, 84118427.

Saunders, M. A., and A. R. Harris, 1997: Statistical evidence links exceptional 1995 Atlantic hurricane season to record sea warming. Geophys. Res. Lett., 24, 1255-1258.

Shapiro, L. J., and S. B. Goldenberg, 1998: Atlantic sea surface temperatures and tropical cyclone formation. J. Climate, 11, $578-590$

Shay, L. K., G. J. Goni, and P. G. Black, 2000: Effects of a warm oceanic feature on Hurricane Opal. Mon. Wea. Rev., 128, 1366-1383.

Tourre, Y. M., B. Rajagopalan, and Y. Kushnir, 1999: Dominant patterns of climate variability in the Atlantic Ocean during the last 136 years. J. Climate, 12, 2285-2299.

Wang, C. Z., D. B. Enfield, S.-k. Lee, and C. W. Landsea, 2006: Influences of the Atlantic warm pool on Western Hemisphere summer rainfall and Atlantic hurricanes. J. Climate, 19, 3011-3028.

Webster, P., G. J. Holland, J. A. Curry, and H.-R. Chang, 2005: Changes in tropical cyclone number, duration and intensity in a warming environment. Science, 309, 1844-1846.

Wentz, F. J., C. L. Gentemann, D. Smith, and D. A. Chelton, 2000: Satellite measurements of sea surface temperature through clouds. Science, 288, 847-850. 